\title{
The interactional management of discipline and morality in the classroom: an introduction
}

\author{
Piera Margutti (Università per Stranieri di Perugia, Italy) \\ Arja Piirainen-Marsh (University of Jyväskylä, Finland)
}

\section{Background}

This special issue of Linguistics and Education investigates a specific domain of activities taking place in classrooms: those in which teacher and students manage expectations concerning the social and moral order of classroom conduct. In their everyday interaction, teachers and students display their sensitivity to the social expectations concerning acceptable behaviour through various verbal and nonverbal means. For instance, teachers may reproach students by explicitly referring to rules of 'correct' behaviour or to their infringement, or they may express disapproval or criticism of student conduct through more implicit means. Students also criticise teachers and hold them accountable for appropriate conduct. The papers included in this volume focus on talk that, either directly or indirectly, deals with violations of the social organization of classroom interaction. Using conversation analysis the authors investigate activities through which teachers and students address some forms of conduct as unacceptable, criticisable or reproachable. The aim of the studies in this volume is to show how these activities surface in talk in the shape of remarks, comments, irony, forms of address, and non-verbal behaviour.

A considerable number of studies addressing the social organisation of the classroom have concentrated on instructional talk, showing how the teacher's authority resides in the unequal distribution of the participants' speaking rights. Drawing on analysis of recorded lessons, Sinclair and Coulthard (1975) identified the 'teaching exchange' (or IRE) as the most representative type of interaction organization in the classroom. Since their seminal study appeared, research in this domain has recognized that the teacher's responsibility for the initial and final move of the exchange accounts for two main features characterizing classroom interaction: (1) the teacher is the main director of interaction, who controls and regulates discourse by allocating turns to students (McHoul, 1978; Lerner, 1995; Iedema, 1996), and (2) the teacher evaluates the students' replies in relation to the form and to the content of the answer (Mehan, 1979; Drew, 1981; Levinson, 1992).

Studies within this tradition have focused in particular on the three-part exchange as the template for classroom interaction embodying its main institutional goal (Mehan, 1979; Cazden, 1986; Mercer, 1995; Galton et al., 1999; Nassaji and Wells, 2000; Nystrand et al., 2003). Recent ethnographic and interaction-based research has broadened this view, showing, for example, how instruction activities can develop through different structures of participation with or without the presence of the teacher (Sahlström, 1999; Thornborrow, 2002; Szymansky, 2003, Seedhouse, 2004; Jones and Thornborrow, 2004). A robust body of research in the ethnographic field has explored the architecture of the entire lesson (see Shultz et al., 1982; Erickson, 1982, Green 2008). Studies comparing larger portions of instruction talk in different settings and also interactions which pupils experience at home have revealed larger types of organization not captured by the IRE model. These studies have also shed light on other activities which nevertheless are relevant components of the interaction that takes place in the classroom (e.g. taking the register, doing lunch administration, various 'off task' activities). From this work, a new perspective on the social and moral order of classrooms emerges. The teacher is the party held responsible for the 
moral order not only in relation to the management of the 'basic turn-allocation apparatus of classroom lessons' (Mehan, 1979: 95), but also in relation to the management of other activities and unauthorised ways of behaving (Macbeth, 1990; 1991) that may occur as 'asides' within instructional sequences or may be enacted per se both by teachers and students.

Most previous research into discipline management and teacher's responses to students' ways of behaving is based on classifications of conduct into self-explicating categories of actions such as "criticism" and "praise" (but see Schultz et. al., 1992; DorrBremme, 1990; and Macbeth, 1990, 1991, who attempt to 'un-package' the construction and interpretation of unprompted and disruptive behaviour). There is extensive literature in the tradition of educational studies on the way in which teacher's praise statements can influence students' motivation, confidence, success in carrying out a specific task, and even control misbehaving children (Kounin, 1970; Martin, 1977; Brophy, 1981 and 1983). Actions such as praise, encouragement or appreciations, and their opposite criticism, are generally linked to other pre-determined variables such as, for instance, the children's socio-economic class, ability levels, and gender, among others.

Similarly, a number of studies in the field of sociology of education have addressed classroom discipline by searching for causes of disruptive behaviour as tied to a number of measurable socio-psychological variables, all external to and somehow pre-determined with respect to the teacher-students interaction in vivo (Descombe, 1984 1985; Cicourel and Kitsuse, 1963, 1968; Cox and Boyson, 1975;). Typically these studies treat students' disorderly behaviour as a self-evident phenomenon, whose causes are researched through accounts provided by teachers, parents, and students after the events have taken place and elicited by means of interview or questionnaires and ethnographic observation. Only few studies so far have employed systematic and detailed empirical observation of classroom interaction in which teachers actually deal with the problem of addressing, referring to, and evaluating students' disruptive conduct, or in which students express criticism or challenge the teacher's authority.

One seminal work in this latter line of research is the work conducted by Schultz, Florio and Erikson (1982) on the disruptive behaviour of American children with an Italian background in pre-school classes in Boston. Drawing from previous ethnographic studies, they adopted a micro-ethnographic approach and a comparative methodology similar to the work by Heath (1983) and Philips (1983), which enabled them to compare sequences of interaction in which children were involved at school and at home with similar participation structures. The study claims that the children's 'interruptive' behaviour at school is evaluated as 'collaborative' in the family context; a circumstance which accounted for the children's 'interruptive' behaviour at school. More recently, Dorr-Bremme (1990) analyzed the social organization of interaction in a primary grade classroom from an ethnographic perspective. He explains the occurrences of students' 'misbehaviour' as related to the absence of specific contextualization cues which teachers inadvertently omit during transitions from one activity to the other. Other, more linguistically oriented studies have explored how teachers' authority or power is enacted through regulative discourse such as different types of directives (Iedema, 1996; Manke, 1997; He, 2000; Buzzelli and Johnston, 2001). Finally, the type of interactional work which teachers and students do when dealing with breeches in the classroom order has been addressed in the work of Macbeth $(1990,1991)$, which investigates teacher's authority in relation to specific practices that deal with the management of classroom discipline, in particular reproaches. This special issue addresses the same domain of practices. Drawing on data from diverse educational environments and applying the conceptual and methodological framework of conversation analysis, the studies in this 
volume investigate how teachers and students invoke, accomplish and manage moral evaluations of classroom conduct through reproaching or criticising others.

\section{Conversation analysis}

Conversation analysis (CA) takes as its starting point the fact that social interaction is orderly and methodically achieved through a set of interactional practices and that these practices can be analysed through close attention to naturally occurring interactions. The focus of attention is on observable patterns in the data; the linguistic and non-linguistic practices (e.g. gazes, facial expressions, gestures, body movement as well as the use spatial resources and artefacts) through which social actions are accomplished and managed. These investigated in order to understand how the core activities of specific settings get done and become recognisable, orderly and acceptable for participants. Conversation analysis is currently used to analyse a wide variety of settings, including classrooms. An extensive body of research is now available which describes patterns of interaction in judicial settings (see e.g. seminal study by Atkinson and Drew, 1979), broadcast media interaction (Clayman \& Heritage, 2002; Hutchby, 1999), medical interactions (Heritage and Maynard, 2007) and various technologically mediated work settings (see Nevile, 2004, Arminen, 2005), to mention but a few.

As one of its key methodological principles, conversation analysis avoids abstract, a priori theorization and categorisation of phenomena. The aim is to ground analytic categories and claims in observable details of interaction. The focus is on the locally produced order by which "social and institutional realities are occasioned, maintained and managed" (Arminen, 2005: 5). This basic tenet in CA methodology enables the analyst to identify and make observable the techniques through which social activity in these settings is organised as well as the resources used by the participants in shaping and interpreting such activity.

Accordingly, studies of educational settings have demonstrated how classrooms function as arenas for participation in activities focused on the construction of knowledge through specific forms of turn organisation (e.g. McHoul, 1978; Lerner, 1985; Seedhouse, 2004) and repair (McHoul, 1990; Macbeth, 2004; Hall 2007); how practices of questioning are oriented to the institutional tasks of teaching and learning as well as to particular classroom agendas and educational values (Jones and Thornborrow, 2004; Sahlström, 1999; Margutti, 2006); and what kinds of resources are drawn upon in negotiating what constitutes acceptable behaviour (Macbeth, 1990, 1991; Thornborrow, 2002).

The papers in this special issue focus on the domain of practices associated with the management of discipline and (co-)construction of the moral order of classroom activities. They draw on video-recorded data of classroom interaction in different settings in terms of school grades (ranging from primary to high school), types of classes (second language teaching, literacy classes, biology lessons and others) languages and local cultures (Finland, Sweden, Italy). All authors use Gail Jefferson's standard transcription conventions, as described in Atkinson and Heritage (1984). When additional symbols are employed, authors have explained their meaning in notes and appendices to each article. All papers apply conversation analysis as the conceptual and methodological framework within which to carry out the analyses, highlighting both the verbal, linguistic and nonverbal, multimodal and sequential aspects of classroom talk. In addressing the specific practices in focus, they also draw from research in linguistics, discourse studies, education and sociology to situate their work within a broader context, and in order to present a multifaceted, yet detailed view of the phenomena they study in situ.

\section{Contributions}


The papers in this volume address the management of the social and moral order of classrooms by analysing and describing actions that display disapproval or otherwise negatively evaluate some (course of) conduct in the classroom. The actions are accomplished in a variety of ways, by verbally addressing the participant(s) responsible for such conduct or by showing attention to it through nonverbal actions. The participants can address breeches to the moral norms and values of the classroom either retrospectively, e.g. through reproaching or criticising some prior conduct, or prospectively, e.g. through directives through which they seek to change a particular course of action. Studies reported here address a variety of interactional phenomena, including gaze, verbal formulations, address forms, irony and shushing, as resources through which teachers - and sometimes students - attend to and display disapproval of some prior or ongoing conduct.

Like previous research on the moral dimension of everyday talk (Pomerantz 1978, Günthner 1996, Drew 1998, Bergman 1998, Edwards 2005), studies in this volume share the view that the moral order of classrooms is intertwined and embedded in the social organisation of classroom life. They examine moral norms and values as interpretative mechanisms which enable the evaluation of people's conduct and attitudes in terms of what is 'good', 'bad', 'right or 'wrong'. Such norms are constructed, negotiated and reconfirmed in social interactions. Classroom talk, as well as interaction in other institutional types of setting is rich in moral elements (see e.g. Macbeth, 1990, 1991; Bergman 1992; Sahlström, forth.). To shed light on the detailed practices through which the normative order of classroom conduct is managed, the papers aim to provide a detailed and technical specification of the actual practices of criticism and reproaching as they are employed in specific local environments in a variety of educational settings. They seek to contribute to the multidisciplinary field of studies on classroom discourse by describing some of the practices through which moral evaluations are accomplished in Italian, Finnish and Swedish classrooms. Practices analysed here reveal the boundaries of acceptable behaviour in classrooms often in quite subtle ways. The full range of these practices as well as their implications to the orderly management of lessons is yet to be discovered. We hope the initial observations documented here will generate more interest in comparing similar practices across settings and cultures.

Margutti's paper investigates one specific format of reproaching whereby teachers address students with explicit descriptions of action to display that the type of behaviour being described has been noticed and is not approved of. This format differs from other reproaching practices used in the classroom in that it makes an explicit reference to the action being reproached through a description of the offence and of its effects. The data come from Italian secondary classrooms. Margutti's analysis shows how reproaches with a descriptionformat exhibit teachers' orientation to a reproachable action as obviously 'wrong' either by emphasizing the consequences of the designated conduct, or by ironizing some of its aspects. In this way the behaviour is portrayed as self-evidently offensive and problematic. Margutti shows that reproaches in the description-format that 'states the obvious' are rather 'extreme' actions, almost edging into accusations. And, as such, they are designed to preempt any response from the recipient. In other words, through a specific formulation of the students' conduct, teachers convey the stance that the problematic action should not have occurred, it has already produced its negative consequences, and the offender or offenders were in the position of avoiding them.

Tainio examines data from Finnish junior secondary classrooms (students aged 13-15) focusing on reproaches that are used in order to silence students and in which gendered address terms are included. Tainio argues that through reproaches including the address term 'boys', the teachers contribute to the construction of the gender category of 'boys' in 
classroom interaction. Thus practices of reproaching are no only tied to institutional identities, but also gendered identities in the joint construction of the moral order of classrooms. Tainio's contribution also investigates the students' responses to the teacher's use of address terms. In their own turns-at-talk, the students sometimes adopt and repeat the address terms for specific interactional ends. These include constructing entertainment by teasing the addressed students as well as the teacher in a humorous way and thus implicitly criticizing the use of gendered address terms in the classroom. The analysis contributes to previous research on gendered order in the classroom by showing that students as well as the teacher actively attend to gender categories, and may also adopt the teacher's practices for playful purposes, thus showing their own agency in interaction.

Also Lehtimaja's study deals with forms of addressing. Building on Macbeth's (1991) analysis of address terms used by the teacher, Lehtimaja focuses on the way in which students use forms of address to criticize or express disapproval of the teacher. Her data comes from videotaped lessons of Finnish as a second language in lower secondary school. Two types of address terms are distinguished: self standing ones and those embedded in different challenging turns. In their interactional contexts the address terms acquire very different meanings and functions. Lehtimaja shows that the difference between the two formats and the rationale behind their occurrence in different sequential contexts is that in the first practice the address term is usually prosodically marked and doesn't require a response by the teacher, whereas in the second practice the teacher often reacts by aligning with the student or by switching to a non-serious mode. According to the way in which address terms are delivered, they seem thus to serve as signals of mitigation and distance, reducing the seriousness of the challenge turn. Like Tainio's paper, the analysis highlights the functional complexity, the situatedness and the social implications of addressing.

Despite their frequent occurrence in classrooms, shushing (i.e. a single or repeated "ssh", done in order to silence someone or something) has received little if any explicit prior research attention. The paper by Sahlström studies what classroom shushings sound like, where they occur, how they are produced, and what their action import is. The analysis is primarily based on Swedish classroom recordings, in first grade and in eighth grade, with additional materials from US classrooms. The paper approaches classroom shushing from an interactional point of view, taking as its starting point an understanding of overlap in conversation, and its resolution. Sahlström elucidates how shushing emerges as most commonly - although not exclusively - the teacher's resource. His analysis shows that shushing is a remarkably precise and economical resource for resolving overlap, i.e. dealing with violations to the norms of participation in the classroom. The analysis identifies and compares different types of shushings, showing that, in terms of the relative success rate in achieving silence, multiple shushings are remarkably more effective than singles. Sahlström's study breaks new ground in classroom research in addressing a previously largely unexplored phenomenon, which is both frequent and intricately tied to the core of practices through which the social order - and the moral order embedded in it - is accomplished in the classroom.

The final paper by Piirainen-Marsh focuses on highly implicit forms of reproaching, describing how irony is used to negatively evaluate student behaviour in sequences where students challenge the teacher's authority through disrupting or resisting the official business of the lesson. The data come from videorecorded Finnish secondary school classrooms where English is the medium of instruction or target of learning (EFL classes). Irony-implicative utterances are examined from two complementary perspectives: (i) the intricate interactional work utterances involve; how utterances are hearable as ironic and how participants negotiate their implications within the sequences of action in which the utterances are occasioned and used, and (ii) the use of irony in the local management of moral orders in the classroom. 
Irony emerges as a flexible resource for dealing with challenging student conduct because of its highly implicit nature. The findings reveal that irony-implicative utterances are used to deal with designedly cheeky utterances by students and invoke the boundaries of acceptable conduct especially at transitional phases during lessons. Irony can also be embedded in instructional questioning sequences, where it serves to convey disapproval or criticism for inappropriate student action. Finally, irony or sarcasm is used in conflictual exchanges to build opposition and manage resistance.

\section{Conclusion}

The studies attempt an initial description and account of social actions, other than those occurring in canonical instruction activities, that normally occur in classrooms, when teachers and students are busy in carrying on their everyday life and institutional activities. Research, so far, has investigated instruction sequences in depth, overshadowing the details of actions in other domains, such as the management of classroom discipline and order. Collectively, the papers argue for conversation analysis (as distinct from other methods for analysing discourse data) as an approach for analysing the way in which teachers' authority and the moral order of the classroom are produced and understood in everyday classroom activities; thus detracting from the view of teacher/student interaction and, in particular, of successful discipline management in the class as being merely the product of the application of abstract, pre-defined norms (Wootton 1986; Maynard \& Clayman 2003). We hope this issue will encourage more researchers to adopt an interactional perspective on the investigation of these domains and contribute to further study of the previously largely neglected, moral dimension of classroom interaction.

\section{References}

Arminen, I. (2005). Institutional interaction. Studies of Talk at Work. Aldershot: Ashgate.

Atkinson, J. M., and Drew, P. (1979). Order in Court. The Organization of Verbal Interaction in Judicial Settings. London: Macmillan.

Atkinson, J. M., and Heritage, J. (Eds.). (1984). Structures of Social Action: Studies in Conversation Analysis. Cambridge, UK: Cambridge University Press.

Bergmann, J. R. (1992). Veiled morality: notes on discretion in psychiatry. In P. Drew and J. Heritage (eds.), Talk at Work: Interaction in Institutional Settings, pp. 137-162. Cambridge: Cambridge University Press.

Bergmann, J. R. (1998). Introduction: Morality in Discourse. Research on Language and Social Interaction 31 (3\&4), 279-294.

Brophy, J. (1981). Teacher praise: a functional analysis. Review of Educational Research Vol 51, 1, 5-32.

Brophy, J. (1983). Classroom organisation and management. Elementary School Journal 83, 265-285. 
Buzzelli, C. \& Johnston, B. (2001). Authority, power, and morality in classroom discourse. Teaching and Teacher Education 17 (8), 873-884.

Cazden, C.B. (1986). Classroom discourse. In M. C. Wittrock (ed.), Handbook of Research on Teaching, pp. 432-463. New York: Macmillan Publishing Company.

Cicourel, A. V. and Kitsuse, J. I. (1963). The Educational Decision-Makers. New York: Bobbs-Merrill.

Cicourel, A. V. and Kitsuse, J. I. (1968). The social organisation of the high school and deviant adolescent careers. In E. Rubington and M. S. Weinberg (eds.), Deviance: The Interactionist Perspective. Toronto: Collier Macmillan.

Clayman, S. and Heritage, J. (2002). The News Interview: Journalists and Public Figures on the Air. Cambridge: Cambridge University Press.

Cox, C. B. and Boyson, R. (eds.) (1975). Black Papers 1975: the Fight for Education. London: Dent.

Descombe, M. (1985). Classroom Control: a Sociological Perspective. London: George Allen \& Unwin.

Dorr-Bremme, D. W. (1990) Contextualization Cues in the Classroom: Discourse Regulation and Social Control Functions. Language in Society, 19(3): 379-402.

Drew, P. (1981). Adults' corrections of children's mistakes: a response to Wells and Montgomery. In P. French and M. Maclure (eds.), Adult-Child Conversation. pp. 244-267. London: Croom Helm.

Drew, P. (1992). Contested evidence in courtroom cross-examination: the case of a trial for rape. In P. Drew and J. Heritage (eds.), Talk at Work: Interaction in Institutional Settings, pp. 470-520. Cambridge: Cambridge University Press.

Drew, P. (1998). Complaints about Transgressions of Misconducts. Research on Language and Social Interaction 31, 295-325.

Drew, P. and Heritage, J. (eds.) (1992). Talk at Work: Interaction in Institutional Settings. Cambridge: Cambridge University Press.

Edwards, D. (2005). Moaning, whining and laughing: the subjective side of complaints. Discourse Studies 7(1): 5-29.

Erickson, F. (1982). Classroom as Improvisation: Relationships between Academic Task Structure and Social Participation Structure in Lessons. In L.C.Wilkinson (ed.), Communicating in the Classroom, pp.153-181. New York: Academic Press.

French, P. and Maclure, M. (Eds.), (1981). Adult-Child Conversation, London: Croom Helm.

Galton, M., Hargreaves, L., Comber, C., Wall, D. and Pell, A. (1999). Inside the Primary Classroom 20 Years On. London: Routledge 
Green, J.,L.,Weade, R. and Graham, J. (1988). Lesson construction and student participation: a sociolinguistic analysis. In J.L.Green and J. Harker (eds.), Multiple Perspective Analyses of Classroom Discourse, pp.11-48. Norwood: Ablex Publishing Corporation.

Green, J.L. and Dixon, C. (2007). Classroom Interaction and Situated Learning. In M. Martin-Jones and A-M. de Mejía, Encyclopedia Of Language And Education, Volume 3, Discourse and Education, pp.759-772. New York: Springer.

Flanders, N. (1970). Analysing teaching behaviour. Reading, Mass.: Addison-Wesley.

Günthner, S. (1996). The prosodic contextualization of moral work. In E. Couper-Kuhlen \& M. Selting (eds.), Prosody in conversation, pp. 271-302. Cambridge: Cambridge University Press.

Hall, J.K. (2007). Redressing the roles of correction and repair in research on second and foreign language learning. The Modern Language Journal 91(4), 511-526.

Hargreaves, D. H. (1967). Social Relations in a Secondary School. London: Routledge \& Kegan Paul.

He, A. W. (2000). The grammatical and interactional organization of teacher's directives: implications for socialization of Chinese American Children. Linguistics and Education 11(2), 119-140.

Heath, S.B. (1983). Ways with Words: Language, life and work in communities and classroom. Cambridge: Cambridge University Press.

Heritage, J. and Maynard, D. eds. (2007). Communication in Medical Care: Interactions between Primary Care Physicians and Patients. Cambridge: Cambridge University Press.

Iedema, R. (1996). Save the Talk for after the Listening.: The Realization of Regulative Discourse in Teacher Talk. Language and Education 10, 82-103.

Hellermann, J. (2003). The interactive work of prosody in the IRF exchange: teacher repetition in feedback moves. Language in Society 32, 79-104.

Kounin, J. (1970). Discipline and Group Management in Classroom. New York: Holt, Rinehart \& Winston.

Lerner, G. (1995). Turn design and the organization of participation in instructional activities. In Discourse Processes, 19, 111-131.

Levinson S.C. (1992). Activity types and language. In P. Drew and J. Heritage (eds.), Talk at Work: Interaction in Institutional Settings, pp. 66-100. Cambridge: Cambridge University Press.

Jones, R. and Thornborrow, J. (2004). Floors, talk, and the organization of classroom activities, Language in Society, 33 (3), 399-423. 
Macbeth, D. (1990). Classroom order as practical action: the making and un-making of a quiet reproach. British Journal of Sociology of Education 11, 2, 189-211.

Macbeth, D. (1991). Teacher authority as practical action. Linguistics and Education 3, 281313.

Macbeth, D. (2004). The relevance of repair for classroom correction, Language in Society, 33 (5), 703-736.

Manke, M.P. (1997). Classroom power relations. Understanding student - teacher interaction. Mahwah, NJ.: Lawrence Erlbaum.

Margutti, P. (2006) “'Are you human beings?' Order and knowledge construction through questioning in primary classroom interaction". Linguistics and Education, 17 (4), 313-346

Margutti, P. (2007) "Riprendere uno studente. Comportamento sociale e deissi nell'interazione in classe". In RIPLA, Rivista di Psicolinguistica Applicata, VII (1-2): pp.1938.

Martin, D. L. (1977). Your Praise can Smoother Learning. Learning 5(6): 43-51.

Maynard D. W. and Clayman S. E. (2003). Ethnometodology and Conversation Analysis. In L.T. Reynolds and N. J. Herman-Kinney (eds.), Handbook of Symbolic Interactionism, Altamira Press. pp?

McHoul, A. (1978). The organization of turns at talk formal talk in the classroom. Language in Society 7 (2), 183-213.

McHoul, A. (1990). The Organization of Repair in Classroom Talk'. Language in Society, 19 (3), 349-378.

Mehan, H. (1979). Learning lessons. Cambridge, MA: Harvard University Press.

Mercer, N. (1995). The Guided Construction of Knowledge. Talk amongst teachers and learners. Clevedon: Multilingual Matters LTD.

Nassaji, H., Wells, G. (2000). What's the use of 'Triadic Dialogue'? An Investigation of Teacher-Student Interaction. Applied Linguistics 21/3, 376-406.

Nevile, M. (2004). Beyond the black box: talk-in-interaction in the airline cockpit. Aldershot: Ashgate.

Nystrand, M., Wu, L.L., Gamoran, A., Zeiser, S., Long, D. (2003). Questions in Time: Investigating the Structure of Dynamics of Unfolding Classroom Discourse. Discourse Processes, 35(2), 135-198.

Philips, S. (1972). Participant structures and communicative competence. In C. Cazden, V. John and D. Hymes (eds.), The Function of Language in the Classroom, 370-394. New York: Teachers College Press. 
Philips, S.U. (1983). The Invisible Culture: Communication in Classroom and Community on the Warm Springs Indian reservation. New York: Longman.

Pomerantz, A. (1978). Attributions of responsibility: Blamings. Sociology 12, 115-121.

Sahlström, F. (1999). Up the hill backwards. On interactional constraints and affordances for equity-constitution in the classrooms of the Swedish comprehensive school. Uppsala Studies in Education No 85. University of Uppsala.

Sahlström, F. (forthcoming). From doing it to doing it right - morals of literacy learning in transition into school. In J. Cromdal \& M. Tholander (eds.), Children, morality and interaction. London: Equinox.

Seedhouse, P. (2004). The interactional organization of the language classroom: a conversation analysis perspective. Malden, MA: Blackwell.

Shultz J. J., Florio S., Erickson F. (1982). Where's the floor? Aspects of the cultural organization of social relationships in communications at home and in school. In P. Gilmore and A. Glatthorn (eds) Children In and Out of School, pp. 88-123, Center for Applied Linguistics, Washington D.C.

Sinclair, J. \& M. Coulthard (1975). Towards an analysis of discourse. The English used by teachers and pupils. London: Oxford University Press.

Szymanski, M. H. (2003). Producing Text through Talk: Question-Answering Activity in Classroom Peer Group. Linguistics and Education 13 (4), 533-563.

Thornborrow, J. (2002). Power Talk. Language and interaction in institutional discourse. Harlow: Pearson Education.

Thornborrow, J. (2003). The Organization of Primary School Children's On-Task and OffTask Talk in a Small Group Setting. Research on Language and Social Interaction, 36 (1), 7 -32 .

Wilkinson, L. C. (ed.). (1982). Communicating in the Classroom, New York: Academic Press.

Wootton A. (1986). Rules in action: orderly features of actions that formulate rules. In J. Cook-Gumperz, W.A. Corsaro e J. Streeck (eds.), Children's Worlds and Children's Language, pp. 147-68. Berlin: Mouton de Gruyter. 